\title{
Article
}

\section{Military veterans and welfare reform: bridging two policy worlds through qualitative longitudinal research}

Scullion, Lisa, Jones, Katy, Dwyer, Peter, Hynes, Celia and Martin, Philip

Available at http://clok.uclan.ac.uk/35736/

Scullion, Lisa, Jones, Katy, Dwyer, Peter, Hynes, Celia and Martin, Philip (2021) Military veterans and welfare reform: bridging two policy worlds through qualitative longitudinal research. Social Policy and Society . ISSN 1474-7464

It is advisable to refer to the publisher's version if you intend to cite from the work. http://dx.doi.org/10.1017/S1474746421000166

For more information about UCLan's research in this area go to http://www.uclan.ac.uk/researchgroups/ and search for <name of research Group>.

For information about Research generally at UCLan please go to http://www.uclan.ac.uk/research/

All outputs in CLoK are protected by Intellectual Property Rights law, including Copyright law. Copyright, IPR and Moral Rights for the works on this site are retained by the individual authors and/or other copyright owners. Terms and conditions for use of this material are defined in the policies page.

\section{CLoK}

Central Lancashire online Knowledge www.clok.uclan.ac.uk

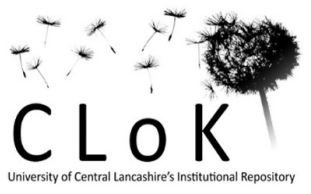


Military veterans and welfare reform: bridging two policy worlds through qualitative longitudinal research

Lisa Scullion*, Katy Jones**, Peter Dwyer***, Celia Hynes**** and Philip Martin*****

* Professor of Social Policy, Sustainable Housing \& Urban Studies Unit (SHUSU), School of Health \& Society, University of Salford, email: 1. scullion@ salford.ac.uk

** Senior Research Associate, Centre for Decent Work \& Productivity, Manchester Metropolitan University, email: katy.jones@mmu.ac.uk

*** Professor of Social Policy, Department of Social Policy and Social Work, University of York, email: peter.dwyer@york.ac.uk

**** Senior Engagement Officer, College for Military Veterans and Emergency Services (CMVES), University of Central Lancashire, email: $\underline{\text { CHynes1@uclan.ac.uk }}$

***** Research Assistant, Sustainable Housing \& Urban Studies Unit (SHUSU), School of Health \& Society, University of Salford, email: p.martin5@salford.ac.uk

\section{Acknowledgements}

This paper is an output from the Forces in Mind Trust (FiMT) funded project: Sanctions, Support \& Service Leavers: Welfare conditionality, social security and transitions from military to civilian life. 


\title{
Military veterans and welfare reform: bridging two policy worlds through qualitative longitudinal research
}

\begin{abstract}
In recent years, there has been an increasing focus in the UK on the support provided to those who have served in the Armed Forces, with the publication of the Armed Forces Covenant (2011), the ten year Strategy for our Veterans (2018) and the creation of the first ever Office for Veterans' Affairs (2019). There is also an important and growing body of research - including longitudinal research - focusing on transitions from military to civilian life, much of which adopts a quantitative approach. At the same time, the UK has witnessed a period of unprecedented welfare reform. However, to date, research focused on veterans' interactions with the social security system has been largely absent, particularly from a qualitative perspective. This article draws on the authors' experiences of undertaking qualitative longitudinal research (QLR) to address this significant knowledge gap. We reflect on how QLR was essential in engagement with policy makers enabling the research to bridge the two parallel policy worlds of veterans' support and welfare reform and leading to significant policy and practice impact.
\end{abstract}

\section{Introduction}

Over the last decade there has been an increasing emphasis in the UK on supporting those who have served in the Armed Forces. In 2011 the UK Government published the Armed Forces Covenant, a 'promise by the nation ensuring that those who serve or who have served in the armed forces, and their families, are treated fairly'. The Armed Forces Covenant asserts that no member of 'the Armed Forces Community' should face disadvantage when accessing public or commercial services, with 'special consideration' deemed appropriate in some cases. The core principles of the Armed Forces Covenant are contained within the Armed Forces Act 2011 and works on the basis that organisations and Government departments pledge their support and make provisions of relevance to their organisation or department. Examples of organisations who have made commitments to the Armed Forces Covenant include the National Health Service (NHS), local government (i.e. some local authorities), some social housing providers, and a range of charities and businesses.

In 2018 the UK Government launched the first ever UK-wide Strategy for our Veterans (HM Government, 2018). The new strategy has a 10-year scope and sets 'the intent for delivery of public services to Veterans across the UK' with the aim that 'every Veteran feels even more valued, supported and empowered and, in accordance with the Armed Forces Covenant ... will never be disadvantaged as a result of their service' (Foreword by Ministerial Covenant and Veterans Board, 2018: 3). The strategy covers six key themes: community and relationships; employment skills and education; finance and debt; health and wellbeing; housing; and law. Policy emphasis on supporting the Armed Forces community was further increased in 2019 through the creation of the first ever Office for Veterans' Affairs (OVA), emphasising lifelong support to veterans. Collectively, all these measures have increased the focus on ensuring Government departments and a range of relevant organisations are appropriately supporting veterans in their transitions to civilian life, creating a significant impetus for ensuring that all the services and systems that veterans may be required to access are appropriate for their needs.

\footnotetext{
${ }^{1}$ https://www.armedforcescovenant.gov.uk/
} 
As part of a commitment to the Armed Forces Covenant, the Department for Work and Pensions (DWP) has a series of initiatives to support current and former Service personnel and their families (DWP and MoD, 2016). This includes locating an Armed Forces Champion (AFC) in every Jobcentre Plus (JCP) district, whose role it is to facilitate 'joint working' between JCP and the Armed Forces community in their district; informing JCP staff about specific Armed Forces initiatives; providing an understanding of issues faced by the Armed Forces community that can present barriers to employment; and promoting the skills, knowledge and experience of the Armed Forces community (ibid). Additionally, the UK Government issues annual reports assessing the progress made against the pledges in the Armed Forces Covenant. In the 2016 report it was stated that the DWP had worked with the Royal British Legion (the UK's largest Armed Forces charity), Atos and Capita (who undertake incapacity benefit assessments) and other stakeholders 'to enhance the service provided to injured Service veterans', particularly for those experiencing Service attributed mental ill health (MoD, 2016: 66).

It is important to recognise that the above changes occurred alongside a period of significant reform to the UK social security system. These reforms have rebalanced the relationship between social rights and responsibilities and a more conditional welfare state has emerged (Dwyer, 2016). More specifically, the Welfare Reform Act (2012) saw the introduction of Universal Credit (UC): 'the most important and fundamental reform since the inception of the welfare state' (Couling, 2018 cited in DWP, 2018: 3). Introduced in 2013, UC replaces four of the existing means-tested social security benefits (Income Support, Jobseekers' Allowance, JSA (Income Based), income-related Employment and Support Allowance, ESA and Housing Benefit) and the two tax credits for working-age people (Child Tax Credit and Working Tax Credit). The roll out of UC finished in December 2018, with new benefit claimants expected to apply for UC. Existing claimants who are receiving 'legacy' benefits or tax credits will be moved over to UC in a process of 'managed migration', which began in July 2019 and is proposed to be completed by the end of 2023. Since its introduction, however, UC has been the subject of criticism in respect of its underlying principles, adequacy of payment levels, and modes of implementation, which have led to new complexities and problems for benefit recipients, including some of the most vulnerable in society (Millar and Bennett, 2017; Wright et al., 2018; Dwyer et al., 2020). Additionally, the ongoing retention of contribution-based unemployment and incapacity benefits in the form of 'New Style JSA' and 'New Style ESA' for those who have sufficient National Insurance contribution records further complicates the contemporary social security landscape. Receipt of these two benefits is restricted to a maximum of six and twelve months respectively, and claimants of these benefits will also be subject to various conditionality requirements depending on their situation (DWP, 2020).

The significant changes in both 'veterans support' and 'welfare reform' outlined above appear to have developed in parallel. With the exception of one recent quantitative study (Burdett et al., 2018; 2019) linking DWP data to existing survey data, veterans' experiences of the benefits system have been neglected in both research and policy development. Burdett et al., (2018) provide useful statistical data on the proportion of veterans who had claimed unemployment benefits or disability benefits at some point since leaving Service (23.4\% and 5.2\% respectively). However, quantitative data are unable to illustrate veterans' lived experiences of navigating the social security system as part of their transition to civilian life, nor their interactions with this system as it undergoes a period of significant reform, and the complexities that this can bring to people's lives. As Millar (2007: 537) states, although 'quantitative data can map out trajectories ... qualitative data can provide an understanding of what lies behind these'. 
Drawing on our involvement in conducting the first UK research to provide an in depth understanding of veterans' experiences of the social security system, we reflect on how adopting a qualitative longitudinal approach was essential in generating insights over time into some of the real lives that lie behind the statistics, whilst also offering a vital means of engaging policy makers. The article begins by introducing the study and presenting some of our key findings. We then turn our attention to reflect upon how QLR enabled us to engage with relevant policy makers and practitioners in a way that might not have otherwise been possible. Through this article we advocate, as others have done, for the role of QLR in providing understandings of experiences within the social security system during a period of significant reform (Dwyer et al., 2018; Wright and Patrick, 2019; Dwyer and Patrick, 2020), but equally as a vital means of providing a more in-depth understanding of transitions from military to civilian life. Overall, we argue that adopting a qualitative longitudinal approach enabled us to bridge the two parallel policy worlds of veterans' support and welfare reform, leading to significant policy and practice impacts.

\section{Addressing a knowledge gap: The Sanctions, Support \& Service Leavers study}

\section{Research design and sample}

In 2017, the Forces in Mind Trust (FiMT) funded a project developed by the authors entitled Sanctions, Support and Service Leavers: Welfare conditionality and transitions from military to civilian life project [hereafter SSSL], which represented the UK's first substantive research to focus on veterans' experiences within the social security system. The project linked to an existing large-scale national project (2013-2018) funded by the ESRC called Welfare Conditionality: Sanctions, Support \& Behaviour Change, and built on the qualitative longitudinal methodological approach of that study (see Dwyer et al., 2018 for further detail). As such, the aims of the SSSL project were to provide an understanding of veterans' diverse pathways into, and out of, the social security system, and to assess the extent to which the conditionality inherent within the benefits system may enhance or inhibit transitions to civilian life. Overall, the SSSL project was designed to provide an evidence base to inform policy and practice in relation to the provision of social security for military veterans.

SSSL adopted purposive non-random sampling techniques (Mason, 2002). The research had ethical approval from the University of Salford research ethics panel, who reviewed our proposed approach to undertaking the research. Participants were recruited through a range of organisations, including Armed Forces charities and other third-sector organisations, Armed Forces and Veterans' Breakfast Clubs, local authorities, and housing/accommodation providers, who disseminated information about the project across their networks. To provide coverage of a range of geographical areas, interviews were primarily carried out in specified areas in the North West and North East of England, Yorkshire and London. The inclusion criteria for the research was those who had served in the UK Armed Forces, who were living within our specified geographical fieldwork areas and were currently claiming one of the following out of work benefits: Employment and Support Allowance (ESA), Jobseeker's Allowance (JSA) or Universal Credit (UC). Veterans who were potentially interested in the project were asked to contact the research team directly, and the principles of informed consent and anonymity underpinned our fieldwork. The research was undertaken over two years (2017-2019), within which two waves of repeat qualitative longitudinal interviews were completed with a 12-month interval. In the first wave of the research (June to November 2017), a total of 68 veterans were interviewed, which formed our starting sample. 
One key concern for researchers undertaking QLR is the issue of attrition (Molloy et al., 2002; Saldana, 2003; Corden and Nice, 2007). To minimise attrition, we employed techniques previously deployed by members of the study team (e.g. through the Welfare Conditionality project), including extensive efforts to record and follow up contact details of those participating in the first wave of interviews. Additionally, although the aim was a 12month interval between interviews, we began contacting participants after around 9-10 months. This enabled us to identify participants who might have been more difficult to recontact and allowed sufficient time to try to reach out to people through the contact details provided (telephone, email, postal address). In some cases, with permission, participants also provided the contact details of a gatekeeper organisation as a second point of contact. In the second wave of our research (July 2018 to January 2019), 52 interviews were conducted, representing a 76 per cent retention rate. Similar to the experience of Corden and Nice (2007: 563 ), in their longitudinal evaluation of the Pathways to Work Pilot, the number of participants who were 'lost' during the course of the research (16 interviewees) was 'too small to look for any patterns in their characteristics'. However, many of those with whom we lost contact or who were unable/unwilling to take part in a second interview were experiencing housing insecurity and/or mental ill health which may have impacted on their continued engagement with the study.

The baseline in our research was the point of transition from the military - this was a pivotal moment in people's lives and from there they could chart what had happened in terms of interactions with the civilian labour market, their relationships, their health and their subsequent interactions with the benefits system. Our first wave of interviews therefore covered significant ground in terms of exploring participants' pre-Service education and employment, their role(s) within the Armed Forces and length of service, their reasons for leaving the Armed Forces and their experience of transition up to the time of interview. Participants were invited to discuss and reflect on their transitions to civilian life in relation to employment, health, housing, personal circumstances and other relevant factors. Specific questions were then asked about factors leading to their engagement with the social security system, and their subsequent experiences of this, including support received (or wish they had received). The initial interview closed by inviting participants to explore what they anticipated would happen in relation to work, education/training, health, personal circumstances and their social security claims over the next twelve months.

The first wave question guide was developed to cover all interviewees; however, there were tailored questions and prompts to enable us to understand experiences of the different types of benefits and related processes e.g. additional questions/prompts for those who had experienced a Work Capability Assessment (WCA) for ESA or had moved from legacy benefits to UC. The question guide was developed by the research team, in consultation with the Project Advisory Group (PAG). From project inception, this group included representatives from Armed Forces charities, the Ministry of Defence (MoD), statutory organisations, and academics. A number of the PAG members were serving personnel or veterans.

For the follow-up interviews, a second question guide was developed. In these interviews we asked participants to reflect on their experiences since our first interview; for example, exploring any changes in relation to their benefit claim (e.g. transition from legacy benefits to Universal Credit, movements off benefits and into paid employment, experiences of WCAs, etc) as well as exploring changes relating to overall health and well-being, and any support received. As with the baseline interviews, the question guide was developed by the research team, with the support of our PAG. By this stage in the project, the Department for Work and Pensions (DWP) had also joined the project's PAG (see discussion below), so questions were also informed by their expertise and policy concerns. 
Each interview lasted approximately one hour, and the majority took place face-toface; however, a small number were undertaken via telephone or Skype where people had come forward to participate but lived outside the core geographical areas of the study or where they had moved to a different geographical area between the first and second interviews. In addition to speaking to veterans individually, we also undertook a small number of joint interviews with spouses (six at first wave; five at second wave). The joint interviews provided additional important insights into the significant role that some spouses were undertaking in caring for their partners, but also in supporting the navigation and management of social security claims. Each participant (including spouses in the joint interviews) received a $£ 20$ shopping voucher to thank them for their time, at each wave of interviews.

\section{Analysis and reporting}

QLR generates rich data sets, which can be challenging to manage and analyse (Corden and Millar, 2007). As Lewis (2007: 550) reflects: 'The volume of data is at once the delight and the challenge of qualitative longitudinal analysis'. The interviews were transcribed verbatim and we used Framework analysis to explore the data (Ritchie and Spencer, 1994; Ritchie, Spencer and O'Connor, 2003). Similar to Corden and Nice (2007), this enabled a mix of both cross-sectional and longitudinal analysis. As noted above, due to attrition, longitudinal analysis was possible for 52 out of the original sample of 68 . However, we share with Corden and Nice (2007: 563) that 'It is unethical not to use information from people who have agreed to take part in research and who expect their views to be taken into consideration'. As such, we included in our findings reports the experiences of those who only participated in a first wave interview.

Within our research reports (Scullion et al., 2018; 2019), we included a mix of findings emerging from the cross-sectional and repeat cross-sectional analysis (Lewis, 2007). The cross-sectional analysis of the first interviews provided important reflections in relation to some of the difficulties that arose in the transitions to civilian life. Key issues included: the impact of mental and physical health issues that were attributed to Service in the Armed Forces (as well as health issues that had developed that were unrelated to their Service), movements in and out of employment, and initial experiences of navigating the benefits system. However, following people forward over time provides an opportunity to understand the ways in which people use, and respond to, the welfare services available to them (Corden and Millar, 2007). As such, through repeat cross-sectional analysis we were able to inform policy makers on aspects of participants' experiences that might not have been apparent without the use of QLR (Corden and Nice, 2007). More specifically, within our final report (Scullion et al., 2019) we included case studies to illustrate how interactions with the social security system could lead to diverse outcomes over time. Case studies are often used within qualitative research (Lewis, 2003), particularly when evidencing policy impacts (Pawson, 2006). Within our study, rather than providing a 'multiplicity of perspectives' (Lewis, 2003: 52), our approach was to present individual 'case narratives' (Lewis, 2007). Here, we provide an overview of two of these case narratives: 'David'2 and 'Paul and Helen'. These individuals were chosen as their experiences typified key themes identified in our analysis relating to the differences in interactions and outcomes depending on the presence or absence of appropriate support.

\footnotetext{
${ }^{2}$ Pseudonyms were used in the case studies to ensure anonymity.
} 


\section{'David': QLR demonstrating where more support is required}

David had served in the Armed Forces for over ten years and left around 30 years previously, after a number of significant tours of active duty. In his late 50s, he had undertaken various jobs (construction, driving, retail) since leaving the Armed Forces. He described a deterioration in his physical health over the years, and had experienced a heart attack a couple of years prior to his first interview. In addition to physical health issues, David was suffering from mental ill health, which he attributed to his time in the Armed Forces. It was at that point that David encountered the benefits system and had made a claim for ESA. However, David had been found 'fit for work' following his (first) WCA and had been placed on Jobseekers Allowance (JSA). Like some of the other veterans in our study, David had also experienced a relationship breakdown. For David this had led to a period of 'sofa surfing' at family and friends' houses.

The combination of 'sofa surfing' and his deteriorating mental health led to referral to a veteran-specific supported accommodation centre, which required him to move to a different geographical location. Although David was in the early stages of his residence there (he had been living there for less than two weeks at the time of the first interview), he was aware that there was a range of support available to him. Indeed, our conversations with staff and other residents indicated that the accommodation helped to link veterans to specialist health care support and education/training opportunities. There was also a good relationship between the accommodation and the local JCP office, where JCP staff were positively supporting a number of residents with their benefits claims. Indeed, at the time of our first interview, David was waiting for a second WCA in order to revisit his eligibility for ESA, instigated following his move to the temporary accommodation.

In our follow-up interview, 12 months later, we discovered that David's second WCA had resulted in him being placed in the ESA Support Group. Whilst evidently relieved by this outcome, David was confused as to how the decision could be so different from the first WCA given that his health status had not changed:

\section{I'd done my assessments down in [previous location] ... I got zero points for anything... Up here [new location], they said you're completely loopy... and then I was getting the severe disability as well (David, Wave B)}

Between his first and second interview, he had also been awarded Personal Independence Payment (PIP). He described a period of relative stability in relation to his benefit claims, alongside improvements in his overall health and well-being. He was also participating in voluntary work. Additionally, David had moved out of the supported accommodation and was now managing his own tenancy.

However, his new property was located within a different local authority area and this change in circumstance had resulted in David being required to claim UC rather than ESA. It was evident that, for David, being transferred to UC had destabilised his life, leading to a sense of confusion and feelings of anxiety, particularly in relation to the reduction in his level of benefit entitlement and variations in payments month to month:

I lost $\$ 240$ a month because I went onto Universal Credit. It's a lot of money to lose... Because Universal Credit covers, I think it's five subjects or something like that, but it doesn't cover the sixth subject, which is severe disability... What I get now, which is really annoying, I get PIP, then I get ESA, so they're giving me some ESA, and then they give me Universal Credit, so I'm getting it coming from all directions. I get a little bit from each one, and it's really hard to manage... It is confusing. I know that I 
didn't get any money last week, but I got whatever it was before that... I don't know where it's coming from. I just look at my bank, oh, they've put that in. Which one that's from, I don't know because I'm technically mad, aren't I? [referring to his ongoing mental health issues]. They don't realise how much - it's a little thing to them, but it's actually big for me ... On ESA, I had no hassle whatsoever. They paid me, left me alone ... Went onto Universal Credit, Jesus, that was it. I was freaking out big time (David, Wave B)

David's account also portrayed the difficulties that can be experienced by some claimants in the move to a digitalised benefits system (Olphert and Damodaran, 2013; Easton, 2014; Beatty and Povey, 2018), as he was critical that the majority of his interactions with the benefits system now took place online with someone he had never met:

She isn't my Work Coach. I haven't got a clue who she is. It's like talking to a robot ... I've got nothing to do with her. She doesn't know me whatsoever ... They've got to make it personal ... I get their notes, 'Please read your Universal [Credit] account. You haven't done this, you haven't done this, you haven't done that. Tell us why you think you are unfit for work'. Hang on, you told me I'm unfit for work... the statements that they write, 'You consider yourself unfit'. No, you've told me I'm unfit. We've had the medicals [referring to WCA]... You have decreed that I'm unfit (David, Wave B)

In addition to broader concerns around digital interactions, David felt that his move from ESA to UC had resulted in subtle shifts in the language used around his 'fitness for work', and he perceived the online messages he received as requiring him to once again prove he was unfit for work, despite the outcome of his most recent WCA.

\section{'Paul' and 'Helen': QLR demonstrating good practice in supporting veterans}

Paul and Helen were jointly interviewed in both waves of repeat interviews. Paul had served in the Armed Forces for over ten years and had been medically discharged around 12 years prior to our first interview. In our first interview, Paul was experiencing a long-term physical health condition. He had also been diagnosed with PTSD, resulting from his service in the Armed Forces. Initially unaware of his mental health issues at the point of leaving service, like many other participants in our study, he had quickly found employment in the civilian labour market. However, both Paul and Helen began to realise that something was wrong, and as his health deteriorated, it negatively impacted on both their relationship and his ability to sustain paid work. This triggered a need to make a claim for social security benefits, but similar to David - his difficulties escalated when he had been assessed as 'fit for work'. At this point, Helen sought the support of the Armed Forces charitable sector, who helped Paul to appeal against his initial WCA decision, and he was subsequently placed in the ESA Support Group:

Helen: He had to go for a-what's it called? Work Capability Assessment? ... and because he could look the doctor in the eye is why they failed him, because he looks physically fit. That's why they stopped the monies.

Paul: I worked for a few years after, tried to deal with what was going on. Didn't really understand what it was or what was happening, and then... We've only been married three years. She basically turned round and said she'd had enough, and then that's when she basically went and found [the Armed Forces charities] ... We challenged every decision that they made, because - paperwork is literally the only 
thing we have to put me to the military ... I had doctors' letters ... We had absolutely every bit of documentation they could have ever wanted... Which is where [Armed Forces charity] came in... I owe [them] everything... It was about three, four weeks after that that I actually got put back on benefits (Paul and Helen, Wave A)

At the time of our first interview, Paul was also receiving specialist support in relation to his PTSD diagnosis from both the Armed Forces charity and the NHS.

Like David, we revisited Paul and Helen 12 months later and it was evident that they had also experienced a number of positive changes in the intervening period. Paul was still in receipt of ESA, and had continued with specialist counselling, leading to improvements in his mental health. Both Paul and Helen had also taken up some voluntary work, and Helen was attending a support group that had been set up by an Armed Forces Charity for partners of veterans experiencing PTSD. However, what was different about Paul and Helen's discussions was that - unlike David - their positive experiences also extended to their recent interactions with the benefits system. More specifically, following their first interview, they had been introduced to their local DWP Armed Forces Champion:

Helen: [The Armed Forces Champion] came out and seen us... [they] said, 'Can I come to the house?... about the time of the [PIP assessment] my husband was getting really anxious, so the [Armed Forces] Champion basically rang them and said, 'Look, he's not going to be able to do it' and rearranged the appointment for us ...

Paul: [the Armed Forces Champion] basically said, 'I'm a friendly face, you've worked with me since the year, let me come with you'. Don't get me wrong, [they] didn't influence the assessment in any way ...

Helen: [They] asked me, 'Was I on Carer's Allowance?' I said no... I said, obviously, I was just plugging on in life ... [They] said, 'Well, maybe we could go through the forms '... I said, 'Yes, okay', and I ended up becoming the carer for my husband ... I get the odd email every now and then [from Armed Forces Champion], just checking in, basically. Seeing how things are and making sure everything's all right (Paul and Helen, Wave B)

As Paul and Helen's account illustrates, the DWP Armed Forces Champion had supported them in a number of significant ways, including making a home visit, accompanying Paul to his PIP assessment, and supporting Helen to make a claim for Carer's Allowance. This experience appeared to be a stark contrast to the remote interactions that David described.

\section{Reflecting on key findings}

Millar (2007: 535) suggests that qualitative longitudinal studies 'present a more complex picture of transitions, and of the factors that trigger them, than do large scale quantitative studies'. Indeed, using QLR enabled us to illustrate experiences that would not have been uncovered through a single 'static' interview or through a survey approach. Given the volume of data and breadth of issues included within the study, space in this article does not permit a detailed presentation of the project findings (see Scullion et al., 2018; 2019 for the full findings and recommendations). However, by drawing on two indicative case studies, we have demonstrated the complexities that qualitative longitudinal research can uncover including the fluctuation and change that can occur in people's live within a relatively short period of one year; something that is not possible when other methodological approaches 
(e.g. cross-sectional or quantitative longitudinal analysis) are employed. Furthermore, the cases presented above illustrate a number of key findings in relation to understanding transitions from military to civilian life over a longer time frame and the specific role that interactions with the social security system can play in improving or diminishing the lived experiences of veterans long after leaving the Services.

When considering military transitions, the qualitative longitudinal analysis provided important insights into the difficulties some Service Leavers face in their transitions to civilian life, particularly where mental ill health is a significant feature within their lives. Discussing the dynamics of poverty and social exclusion, Millar (2007: 535) notes that 'Transitions are not necessarily temporally fixed, discrete and clearly definable events'. However, this could equally apply to the dynamics of the transition from military to civilian life. Indeed, as Pranger, Murphy and Thompson (2009: 159) suggest: 'There are no commonly accepted definitions for the start and end of transition to civilian life'. The fact that David and Paul had both left the Armed Forces a number of years previously, but that issues relating to mental ill health had only been identified in more recent years, supports the notion that to conceptualise military transitions according to set temporal parameters is difficult (and arguably misplaced). Our findings support recent shifts within the veterans' policy world that emphasises lifelong support for those who have served in the Armed Forces.

The research focused specifically on experiences of the social security system and brought to light some of the difficulties experienced by our participants in their interactions with this regime. More specifically, our analysis highlighted important concerns around how Service-related impairment was being approached within the WCA process. Both David and Paul had negative experiences of the WCA, with the longitudinal analysis further exposing previously noted flaws in the implementation and outcomes of WCAs (rf. e.g. Morris, 2011; Dwyer, 2017), but also - in David's case - inconsistencies between different geographical areas. Inconsistencies were also evident in relation to interactions with Work Coaches and/or Armed Forces Champions, with Paul and Helen's account clearly demonstrating the substantive value the DWP Armed Forces Champion role can bring when delivered effectively. Our longitudinal approach also enabled us to explore the experiences of veterans who were transitioning from legacy benefits to $\mathrm{UC}$, highlighting how this transition can impact negatively if support is lacking. As Thomson (2007: 572) argues, QLR 'offers the possibility of developing more complex and thus realistic understandings of ... the intended and unintended consequences of policies themselves'. Looking at both David and Paul's accounts, it is evident that with appropriate support, both had experienced improvements in their mental health and a sense of stability in their benefits claims. However, our longitudinal analysis demonstrated how easily this could be disrupted by events or changes, with unintended consequences for people's health and well-being. While Paul's anxiety over his PIP assessment had been alleviated by the intervention of the Armed Forces Champion, David's experience of change had been less positive. Indeed, David's account highlighted the disruption to his sense of stability that had occurred following the transition from ESA to UC, including confusion about reduced payments but also the replacement of more positive face to face interactions with digital interactions.

Overall - and referring back to the stated purpose of the Armed Forces Covenant our findings highlighted that some veterans did appear to be disadvantaged in their interactions with the benefits system, and although many of the issues that were raised apply to the UK civilian population, they were sometimes amplified by the distinctive characteristics of active Service in the Armed Forces. For example, the challenges of moving to civilian life from an 'insulated' culture, the impact of injuries and/or trauma, issues relating 
to continuity of employment, and pressures on relationships during and after Service (Scullion et al., 2018; Hynes et al., 2020).

\section{Impacting policy and practice through qualitative longitudinal research}

The SSSL reports (Scullion et al., 2018, 2019) made a series of practical recommendations, which included:

- Ensuring that guidance on the social security system is included as a routine part of the resettlement support provided to those leaving the UK Armed Forces;

- Ensuring that Armed Forces background is consistently recorded by JCP and that disclosure of an Armed Forces background triggers consideration of how best to support people, including signposting veterans to relevant organisations that can provide support with transition issues;

- Providing additional, tailored and/or enhanced support to veterans as they transition from legacy benefits to UC;

- Reviewing the assessment process to ensure that assessors are suitably qualified to assess mental and physical health issues related to service in the Armed Forces; and

- Reviewing the Armed Forces Champion role to ensure consistency in the support provided through the role.

Both the interim (Scullion et al., 2018) and final report (Scullion et al., 2019) reached a wide audience, including citation within parliamentary debate ${ }^{3}$ and dissemination at a range of significant forums both within and outside the military arena (for example, citation within the report focusing on poverty in the UK published by the United Nations Special Rapporteur on Extreme Poverty and Human Rights, Professor Philip Alston). In relation to policy and practice impact, the project helped support a multi-million investment in the Government's Spending Round 2019, which included 'increasing the number of Armed Forces champions to support veterans' (HM Treasury, 2019: section 2.18). Additionally, a commitment was made by the DWP and MoD to work collaboratively to provide further guidance on the benefits system to Armed Forces Service Leavers (FiMT, 2020). With regards to the concerns raised around benefits assessment processes, a commitment was also made in relation to the development of training around assessing the specific mental and physical health issues related to service in the Armed Forces (ibid).

Reflecting on the delivery of the research, it is evident that a qualitative longitudinal approach was vital in enabling the positive policy maker engagement that led to this subsequent impact. Lewis (2007) talks about change occurring as part of the research process itself. Although Lewis is reflecting on participants' increasing willingness to share details as rapport builds over time, this project demonstrates that this can also be true of the relationship building that longitudinal research enables with key policy and practice stakeholders. Significantly, our relationship moved from a position of some initial reluctance to engage on the part of policy makers, to one of significant engagement with the research team, supporting real policy change. Although initial invitations to feed into the project were declined, the research team continued to communicate with the DWP about the project, including the opportunity for pre-publication sight of the interim report. Following the interim report, we established regular constructive dialogue with the DWP to discuss the findings but also to enable them to contribute to the next phase of the research. This included

\footnotetext{
${ }^{3}$ Veterans: Universal Credit, oral answers to questions, Defence, House of Commons, $8^{\text {th }}$ July 2019: https://www.theyworkforyou.com/debates/?id=2019-07-08a.4.5
} 
contributing questions to the second wave interview schedule and facilitating access to JCP staff to take part in a series of focus groups. We believe that this positive engagement was in part due to the publication of interim findings, a process that helps provide policy makers with early access to emerging findings (Corden and Nice, 2007). Our interim report was accompanied by an interim findings event, whereby representatives from both the DWP and MoD were able to join a panel to discuss the emerging findings. However, we believe that the positive engagement also stems from our commitment to identifying good practice in supporting veterans and practical recommendations for improving policy and practice. As such, policy and practice stakeholders were able to see the potential benefits of engaging in the project and learn from exemplars of good practice in current provision (e.g. the intervention of an Armed Forces Champion for Paul and Helen); in this way providing a basis for building an improved support offer.

\section{Conclusions}

This article has drawn on the authors' experiences of undertaking the first substantive piece of QLR focused on veterans' engagement with the UK social security system. The project addressed a significant knowledge gap, as this topic was neglected both in the literature on welfare reform and military transitions. Through our focus on two 'policy worlds' that have largely developed in parallel, we have identified several features in each that can frustrate transitions into civilian life. The richness of the insights provided through a QLR approach adds to the contributions from those exploring similar issues quantitatively (Burdett, 2018; 2019). In further research, there would be significant merit in combining quantitative with qualitative longitudinal research, embracing the merits of both methodologies and providing a fuller picture.

In this article, we have discussed the policy engagement process, which we hope will provide some useful insights to help inform other researchers keen to engage with policymakers. Although the SSSL project has garnered policy and practice interest and resulted in some tangible change, we believe that the findings, and subsequent commitments from policymakers, are not an end point; rather, they represent the beginning of our collective efforts (i.e. the research team and policymakers) to ensure that the social security system appropriately supports veterans and their families. However, it is also important to recognise that many of the issues highlighted in our research relate equally to the UK civilian population who are navigating this period of significant welfare reform. As such, the application of many of our recommendations has the potential to improve experiences of the social security system for all claimants.

\section{References}

Alston, P. (2019) Visit to the United Kingdom of Great Britain and Northern Ireland: Report of the Special Rapporteur on extreme poverty and human rights, online at: https://undocs.org/A/HRC/41/39/Add.1

Beatty, C. and Povey, L. (2018) Universal Credit in Rotherham: a transition to full service. Project Report. Sheffield: Sheffield Hallam University.

Burdett, H. Fear, N. T., MacManus, D., Wessely, S., Rona, R. J., Greenberg, N. (2019) 'Unemployment and benefit claims by UK veterans in the new millennium: results from a record linkage study', Occup Environ Med. 76(10): 726-732.

Burdett, H., MacManus, D., Fear, N., Rona, R. and Greenberg, N. (2018) Veterans and benefits: Relationships between social demographics, Service characteristics and mental health with unemployment and disability benefit usage by GB ex-Service 
personnel, online at: https://www.fim-trust.org/wpcontent/uploads/2018/05/20180511-DWP-KCMHR-data-linkage-report-FINAL.pdf

Corden, A. and Millar, J. (2007) 'Qualitative Longitudinal Research for Social Policy Introduction to Themed Section', Social Policy and Society, 6(4): 529-532.

Corden, A. and Nice, K. (2007) 'Qualitative longitudinal analysis for policy: incapacity benefits recipients taking part in Pathways to Work', Social Policy and Society, 6(4), pp. 557-569.

DWP (2018) Universal Credit Programme Full Business Case Summary, available at: https://assets.publishing.service.gov.uk/government/uploads/system/uploads/attachme nt_data/file/725477/uc-business-case-summary.pdf.

DWP (2020) Guidance: Universal Credit and you, London, Department for Work and Pensions, available at: https://www.gov.uk/government/publications/universal-creditand-you/draft-uc-and-you

DWP and MoD (2016) Guidance: Armed Forces access to Jobcentre Plus services and armed forces champions, online at:

https://www.gov.uk/government/publications/jobcentre-plus-services-for-the-armedforces-and-their-families/armed-forces-enhanced-access-to-jobcentre-plus-servicesand-armed-forces-champions.

Dwyer, P. (2016) 'Citizenship, conduct and conditionality: sanction and support in the $21^{\text {st }}$ century UK welfare state', in M. Fenger, J. Hudson and C. Needham (eds) (2016) Social Policy Review 28, Bristol: SPA/The Policy Press, pp. 41-62.

Dwyer, P. (2017) 'Rewriting the contract? Conditionality, welfare reform and the rights and responsibilities of disabled people', in D. Horsfall and J. Hudson [eds], Social Policy in an Era of Competition: from global to Local Perspectives, Bristol: The Policy Press, pp135-148.

Dwyer, P., Batty, E., Blenkinsopp, J., Fitzpatrick, S., Fletcher, D., Flint, J., Johnsen, S., Jones, K., McNeill, J., Scullion, L., Stewart, A. and Wright, S. (2018) Final findings report: Welfare Conditionality Project 2013-2018, York: Welfare Conditionality Project, online at: http://www.welfareconditionality.ac.uk/wpcontent/uploads/2018/06/40475_Welfare-Conditionality_Report_complete-v3.pdf

Dwyer, P. and Patrick, R. (2020) 'Little and large: methodological reflections from two qualitative longitudinal policy studies on welfare conditionality', in Longitudinal and Life Course Studies, available on Fasttrack at https://www.ingentaconnect.com/content/bup/llcs/pre-prints/content-llcsd1900051

Dwyer, P., Scullion, L., Jones, K., McNeill and Stewart, A.B. (2020) 'Work, welfare, and wellbeing: The impacts of welfare conditionality on people with mental health impairments in the UK', Social Policy \& Administration, 54(2): 311-326

Easton C., (2014) "Welfare that Works? The Universal Credit information technology system and disabled people", European Journal of Current Legal Issues, 20(3), Web JCLI.

FiMT (2020) Forces in Mind Trust (FiMT) 2019 Impact Report, online at: https://s31949.pcdn.co/wp-content/uploads/20200717-FiMT-Electronic-ImpactReport-2019.pdf

HM Government (2018) The Strategy for our Veterans, online at: https://assets.publishing.service.gov.uk/government/uploads/system/uploads/attachme nt_data/file/755915/Strategy_for_our_Veterans_FINAL_08.11.18_WEB.pdf

HM Treasury (2019) Spending Round 2019, online at: https://www.gov.uk/government/publications/spending-round-2019document/spending-round-2019 
Hynes, C., Scullion, L., Lawler, C., Boland, P. and Steel, R. (2020) Lives in transition: Returning to civilian life with a physical injury or condition: Interim report, Preston/Salford: University of Central Lancashire/University of Salford.

Lewis, K. (2003) 'Design Issues', in J. Ritchie and J. Lewis (eds) Qualitative Research Practice: A Guide for Social Science Students and Researchers, London: Sage, pp5676.

Lewis, J. (2007) ‘Analysing Qualitative Longitudinal Research in Evaluations', Social Policy and Society, 6(4): 545-556.

Molloy, D. and Woodfield, K., with Bacon, J. (2002) Longitudinal Qualitative Research Approaches in Evaluation Studies, Department for Work and Pensions Working Paper No. 7, London: HMSO.

Mason, J. (2002) Qualitative researching. London: Sage.

Millar, J. (2007) 'The Dynamics of Poverty and Employment: The Contribution of Qualitative Longitudinal Research to Understanding Transitions, Adaptations and Trajectories, Social Policy and Society, 6(4): 533-544.

Millar, J. and Bennett, F. (2017) 'Universal Credit: assumptions, contradictions and virtual reality', Social Policy and Society, 16(2): 169-182.

MoD (2016) Proudly Supporting Those Who Serve: The Armed Forces Covenant Annual Report 2016, online at:

https://www.gov.uk/government/uploads/system/uploads/attachment_data/file/588140 30012016_AFC_Report_FINAL_WEB.PDF.

Morris, S. (2011) 'Government round up', Journal of Poverty and Social Justice 19(2): 193198.

Olphert, W., and Damodaran, L. (2013) 'Older People and Digital Disengagement: A Fourth Digital Divide?', Gerontology, 59: 564-570.

Pawson, R. (2006) Evidence-based Policy: A Realist Perspective, London: Sage.

Pranger, T., Murphy, K. and Thompson, J. M. (2009) 'Shaken world: Coping with transition to civilian life', Canadian Family Physician, 55(2): 159-161.

Ritchie, J. and Spencer, L. (1994) 'Qualitative data analysis for applied policy research', in A. Bryman and R. G. Burgess (eds) Analyzing qualitative data, London: Routledge, pp.173- 194.

Ritchie, J., Spencer, L. and O'Connor, W. (2003) 'Carrying out qualitative analysis', in J. Ritchie and J. Lewis (eds) Qualitative Research Practice, London: Sage, pp 219-262.

Saldana, J. (2003) Longitudinal Qualitative Research: Analyzing Change Through Time, Walnut Creek CA: AltaMira Press.

Scullion, L., Dwyer, P., Jones, K., Martin, P. and Hynes, C. (2019) Sanctions, Support and Service Leavers: Social security benefits, welfare conditionality and transitions from military to civilian life: First wave findings, Salford: University of Salford.

Scullion, L., Dwyer, P., Jones, K., Martin, P. and Hynes, C. (2018) Sanctions, Support and Service Leavers: Social security benefits, welfare conditionality and transitions from military to civilian life: First wave findings, Salford: University of Salford.

Thomson, R. (2007) 'The Qualitative Longitudinal Case History: Practical, Methodological and Ethical Reflections, Social Policy and Society, 6(4): 571-582.

Wright, S., Dwyer, P., Jones, K., McNeill, J.M., Scullion, L. and Stewart, A.B.R. (2018) Final findings: Universal Credit, Research Briefing for the Welfare Conditionality Project, available at: http://www.welfareconditionality.ac.uk/wpcontent/uploads/2018/05/40414-Universal-Credit-web.pdf.

Wright, S. and Patrick, R. (2019) 'Welfare conditionality in lived experience: aggregating qualitative longitudinal research', Social Policy and Society, 18(4): 597-613. 
